\title{
Relationship between bone mineral density and fragility fracture risk: a case-control study in Changsha, China
}

Hong-Li Li ${ }^{1}, 2$, Yi Shen ${ }^{3}$, Li-Hua Tan", Song-bo Fu², Ru-Chun Dai', Ling-Qing Yuan', Zhi-Feng Sheng ${ }^{1}$, Zhong-Jian Xie ${ }^{1}$, Xian-Ping Wu' ${ }^{1}$ Er-Yuan Liao ${ }^{1}$, Xu-Lei Tang ${ }^{2}$ and Xi-Yu Wu ${ }^{1 *}$

\begin{abstract}
Background: Fragility fracture is associated with bone mineral density (BMD), and most databases used in related researches are instrument-matched. Little is known about the relationship between BMD and fragility fracture risk of native Chinese, especially using local databases as reference databases.

Objective: To investigate relationship between BMD and risk of fragility fracture in native China.

Methods: 3,324 cases, including 2,423 women (67.7 \pm 8.9 years) and 901 men (68.4 \pm 11.6 years) having radiological fragility fractures and 3,324 age- and gender-matched controls participated in the study. We measured BMD at posteroanterior spine and hip using dual-energy X-ray absorptiometry (DXA), calculated BMD measurement parameters based on our own BMD reference database.

Results: BMDs and mean T-scores were lower in case group (with clinical fragility) than in control group (without clinical fragility). In patients with fragility fractures, prevalence of lumbar osteoporosis, low bone mass, and normal BMD were $78.9 \%, 19.3 \%$, and $1.8 \%$, respectively, in women, and 49.5, $44.8 \%$, and $5.7 \%$, respectively, in men. In hip, these prevalence rates were $67.2 \%, 28.4 \%$, and $4.4 \%$ in females, and $43.2 \%, 45.9 \%$, and $10.9 \%$ in males, respectively, showing differences between females and males. Multivariate Cox regression analysis showed that after adjusting age, height, weight, and body mass index, fracture hazard ratio (HR) increased by $2.7-2.8$ times (95\% $\mathrm{Cl} 2.5-3.1)$ and 3.6-4.1 times (95 \% Cl 3.0-5.1) for women and men respectively with decreasing BMD parameters. In both sexes, risk of fragility fracture increased approximately $1.6-1.7$ times ( $95 \% \mathrm{Cl} 1.5-1.8)$ for every $1 \mathrm{~T}$-score reduction in BMD.
\end{abstract}

Conclusions: Risk of clinical fragility fracture increases with decreasing BMD measurement parameters and anthropometric indicators in native China, and fracture HR varies from gender and site.

Keywords: Fragility fracture, Osteoporosis, Bone mineral density, T-score, Fracture risk

\footnotetext{
* Correspondence: wuxiyu640@csu.edu.cn

'National Clinical Research Center for Metabolic Diseases, Department of Metabolism and Endocrinology, Hunan Provincial Key Laboratory for Metabolic Bone Diseases, The Second Xiangya Hospital, Central South University, No.139 Middle Renmin Road, 410011 Changsha, Hunan, PR China Full list of author information is available at the end of the article
}

(c) The Author(s). 2021 Open Access This article is licensed under a Creative Commons Attribution 4.0 International License, which permits use, sharing, adaptation, distribution and reproduction in any medium or format, as long as you give appropriate credit to the original author(s) and the source, provide a link to the Creative Commons licence, and indicate if changes were made. The images or other third party material in this article are included in the article's Creative Commons licence, unless indicated otherwise in a credit line to the material. If material is not included in the article's Creative Commons licence and your intended use is not permitted by statutory regulation or exceeds the permitted use, you will need to obtain permission directly from the copyright holder. To view a copy of this licence, visit http://creativecommons.org/licenses/by/4.0/. The Creative Commons Public Domain Dedication waiver (http://creativecommons.org/publicdomain/zero/1.0/) applies to the data made available in this article, unless otherwise stated in a credit line to the data. 


\section{Background}

Osteoporosis is an age-related disease, characterized by decreased bone mass and damage to the microstructure of bone tissue, leading to decreased bone strength and increased risk of fractures. The main serious consequence of osteoporosis is fragility fracture. Fifty-six million people worldwide were estimated to have sustained a fragility fracture in 2000 [1]. Fractures may cause disability and loss of self-care ability, and even result in death [2-5]. Severe fractures are estimated to cause up to $30 \%$ additional mortality [4]. Osteoporosis and fragility fractures entail a heavy economic burden on patient's family and society as a whole [6-9]. Epidemiological surveys have shown that bone mineral density (BMD), prevalence of osteoporosis, and incidence of fragility fractures, differs among different racial and ethnic groups and regions [10-15]. For example, the prevalence of osteoporosis and incidence of fragility fractures are much higher in white people than in black people [10, 11]. Canadians have a significantly lower incidence of hip fracture than Americans and Germans [13]. The incidence of fragility fractures is lower in Asians than in white people [10, 12], while that of fragility fractures is much lower in Beijing than in the rest of China, Taiwan and Hong Kong [14, 15].

In developed western countries such as the United States and Canada, incidence of fragility fractures in white people is declining year by year $[3,16,17]$. However, in developing countries such as China, incidence of fragility fractures is continuously and rapidly increasing with escalating urbanization and rapid aging of the population $[15,18]$. It is estimated that by 2050 , half of fragility fractures worldwide will occur in Asia, mainly in China [19]. Prospective studies have shown that low BMD is the main important determinant of fragility fractures [20, 21], and dual-energy X-ray absorptiometry (DXA) measurements of BMD are a powerful predictor of the risk of fragility fractures in individuals of different races $[22,23]$, because this risk increases with decreasing BMD. Many studies have shown that fragility fracture risk will increase by one-to-three times if BMD reduced by one standard deviation [24-26]. However, in mainland China, the relationship between BMD and fragility fracture risk in vulnerable bone sites, such as lumbar spine and hip, remains unknown. Most of the databases used in other related articles are instrument-matched reference databases, derived from different ethnicities and regions, these factors will affect validity of BMD [27, 28]. In our laboratory, we have established a proprietary BMD reference database, which is more reliable for detection for southern Chinese compared with instrumentmatched Asian reference databases [27, 28]. We conducted this research on our database and obtained the authentic BMD T-scores. We used DXA to measure
BMDs and $T$-scores of lumbar spine and hip in 3,324 patients with a variety of clinical fragility fractures as well as the 3,324 controls. Based on these data, the purpose of this paper is to understand relationship between BMD measurement parameters and risk of fragility fractures in mainland China, as well as the distribution of BMD $T$-scores and prevalence of osteoporosis in fragility fracture patients.

\section{Methods and materials}

\section{Study design and population}

The study was performed in Xiangya Second Hospital, Central South University, Changsha, China, from March 2011 to December 2018. Patients with a variety of fractures diagnosed on radiography in our hospital were potential subjects for case group. The inclusion criteria for patients with fragility fractures were symptomatic vertebral or other fractures sustained with little damage (i.e., falls from standing or less than standing height) or without falling down. Vertebral fractures were confirmed on lateral vertebral radiographs in accordance with semiquantitative method [29]. Patients with following conditions were excluded: traumatic fractures caused in accidents (such as car accidents or falls from above chair height), pathological fractures due to cancer, and fractures of fingers, toes, ankles, face or skull. A total of 3,324 patients, including 2,423 females and 901 males, met the inclusion criteria were included. Of these, 2,577 were spinal fractures, 360 were femoral neck fractures, and 387 were other fractures (such as forearm, wrist, proximal humerus, rib, tibia, and shoulder fractures, but excluding spine and hip fractures).

We also recruited 3,324 community residents as control group from Changsha City. The control group consisted of people who had received physical examination or sought medical care in our hospital. The control and case groups were matched for age and gender in 1:1 ratio. The inclusion criteria for control group were as follows: no history of low- or high-damage fractures and no vertebral deformities on lateral vertebral radiographs. Subjects with osteosclerosis and abnormal increase in BMD and those with skeletal fluorosis were also excluded. This study was approved by the Ethics Committee of Second Xiangya Hospital affiliated to Central South University, and each participant signed an informed consent.

\section{BMD measurement}

BMDs and $T$-scores were measured with DXA fan-beam bone densitometer (Hologic Delphi A; Hologic, Bedford, MA, USA) at posteroanterior (PA) spine (L1-L4) and hip. If vertebral body of the fracture patients was artificial bone cement filler or metal supports after surgery, these vertebrae were excluded in analysis. If patient has 
a fracture or artificial joint replacement surgery on left femoral neck, measured the right hip. If bilateral femoral neck fractures on the patient, abandon the hip measurement. Using the Root mean square coefficient of variation (RMSCV) method, the in vivo accuracy deviations measured by twice BMD in 33 subjects were $0.86 \%$ for PA spine and $0.83 \%$ for total hip. The long-term $(>17$ years) coefficient of variation for daily controlled spinal phantom scans was less than $0.45 \%$. Sex-specific BMD $T$-scores were calculated using our own female and male BMD reference database [27, 28]. According to the World Health Organization (WHO) definition [30], compared with peak BMD of the same gender, if subjects BMD $T$-score $>-1.0$, diagnosed as normal BMD; $T$-score $\leq-1.0$ to $>-2.5$ and $\leq-2.5$, were determined to be osteopenia and osteoporosis, respectively.

\section{Statistical analysis}

All calculations were performed using SPSS V17.0 for Windows software (SPSS Inc., Chicago, IL, USA). The one-way ANOVA was used to compare the differences of BMD and $T$-scores between case groups (vertebral fracture, hip fracture, and other fractures groups) and control groups. Cox proportional hazard regression models were used to analysis association between different factors and fragility fractures risk. We used univariate and multivariate analysis to calculate hazard ratio (HR) with their corresponding $95 \%$ confidence interval (CI). In multivariate analysis, we adjusted for age, age at menopause, years since menopause, body height, body weight, and body mass index. $\mathrm{X}^{2}$ test was used to compare the prevalence of osteoporosis, osteopenia, and normal BMD between men and women. $P<0.05$ was taken to indicate a statistically significant effect.

\section{Results}

\section{Baseline characteristics}

Baseline characteristics of the study subjects are shown in Table 1. Since the age of each individual in case group was exactly matched with that of control subject, the average ages of women and men in case group were identical to those in control group. The average ages of women and men in case group were $67.7 \pm 8.9$ years (range, 45-95 years) and 68.4 \pm 11.6 years (range, 45-93 years) respectively. For both men and women, BMD at different skeletal sites and mean $T$ - scores were significantly lower in case group than in control group. The mean lumbar spine BMD in both women and men were significantly lower in vertebral fracture subgroup than in hip fracture and other subgroups. The average BMD and $T$-scores at different skeletal sites were significantly greater in other fracture subgroup than in vertebral and hip fracture subgroups.

\section{Relation of BMD $T$-score with age}

Figure 1 shows the distribution and $95 \%$ confidence interval of BMD $T$-scores of fracture patients with age, of which female fracture spine and hip $T$-scores decline with increasing age. In $95 \%$ of patients with various fragility fracture, lumbar spine $T$-scores and hip $T$-scores

Table. 1 Comparison of baseline characteristics among cases of fractures and controls

\begin{tabular}{|c|c|c|c|c|c|}
\hline \multirow[t]{2}{*}{ Variable } & \multirow[t]{2}{*}{ Control } & \multirow[t]{2}{*}{ Case } & \multicolumn{3}{|l|}{ Fracture subgroup } \\
\hline & & & Vertebral fracture & Hip fracture & Other fractures \\
\hline \multicolumn{6}{|l|}{ Female } \\
\hline$n$ & 2423 & 2423 & 1819 & 268 & 336 \\
\hline Age (years) & $67.7 \pm 8.9$ & $67.7 \pm 8.9$ & $68.2 \pm 8.8$ & $69.4 \pm 9.0$ & $63.7 \pm 8.3^{c}$ \\
\hline PA-BMD $\left(\mathrm{g} / \mathrm{cm}^{2}\right)$ & $0.822 \pm 0.132$ & $0.629 \pm 0.111^{\mathrm{a}}$ & $0.609 \pm 0.102^{b}$ & $0.660 \pm 0.109$ & $0.712 \pm 0.113^{c}$ \\
\hline Hip-BMD $\left(\mathrm{g} / \mathrm{cm}^{2}\right)$ & $0.743 \pm 0.115$ & $0.584 \pm 0.113^{\mathrm{a}}$ & $0.574 \pm 0.110$ & $0.566 \pm 0.100$ & $0.650 \pm 0.113^{c}$ \\
\hline PA T-score & $-1.48 \pm 1.19$ & $-3.24 \pm 1.00^{\mathrm{a}}$ & $-3.42 \pm 0.92$ & $-3.26 \pm 0.85$ & $-2.49 \pm 1.02^{c}$ \\
\hline Hip T-score & $-1.38 \pm 1.12$ & $-2.93 \pm 1.10^{\mathrm{a}}$ & $-3.02 \pm 1.08$ & $-3.10 \pm 0.98$ & $-2.28 \pm 1.10^{c}$ \\
\hline \multicolumn{6}{|l|}{ Male } \\
\hline$n$ & 901 & 901 & 758 & 92 & 51 \\
\hline Age (years) & $68.4 \pm 11.6$ & $68.4 \pm 11.6$ & $68.4 \pm 11.5$ & $70.5 \pm 12.9$ & $65.0 \pm 10.2^{c}$ \\
\hline PA-BMD $\left(\mathrm{g} / \mathrm{cm}^{2}\right)$ & $0.914 \pm 0.114$ & $0.718 \pm 0.113^{\mathrm{a}}$ & $0.707 \pm 0.103^{b}$ & $0.761 \pm 0.148$ & $0.803 \pm 0.127^{c}$ \\
\hline Hip-BMD $\left(\mathrm{g} / \mathrm{cm}^{2}\right)$ & $0.865 \pm 0.101$ & $0.693 \pm 0.123^{a}$ & $0.689 \pm 0.117$ & $0.661 \pm 0.141$ & $0.807 \pm 0.111^{c}$ \\
\hline PA T-score & $0.05 \pm 1.02$ & $-2.51 \pm 1.01^{\mathrm{a}}$ & $-2.61 \pm 0.92^{b}$ & $-2.12 \pm 1.32$ & $-1.75 \pm 1.14^{c}$ \\
\hline Hip T-score & $-0.09 \pm 0.92$ & $-2.31 \pm 1.12^{\mathrm{a}}$ & $-2.34 \pm 1.07$ & $-2.60 \pm 1.29$ & $-1.27 \pm 1.01^{c}$ \\
\hline
\end{tabular}

$P A-B M D$ posteroanterior $(\mathrm{PA})$ spine bone mineral density

${ }^{\mathrm{a}} P=0.000$ compared with control

${ }^{\mathrm{b}} P=0.005-0.000$ compared with hip and other fractures

${ }^{c} P=0.005-0.000$ compared with vertebral and hip fractures 
(a)

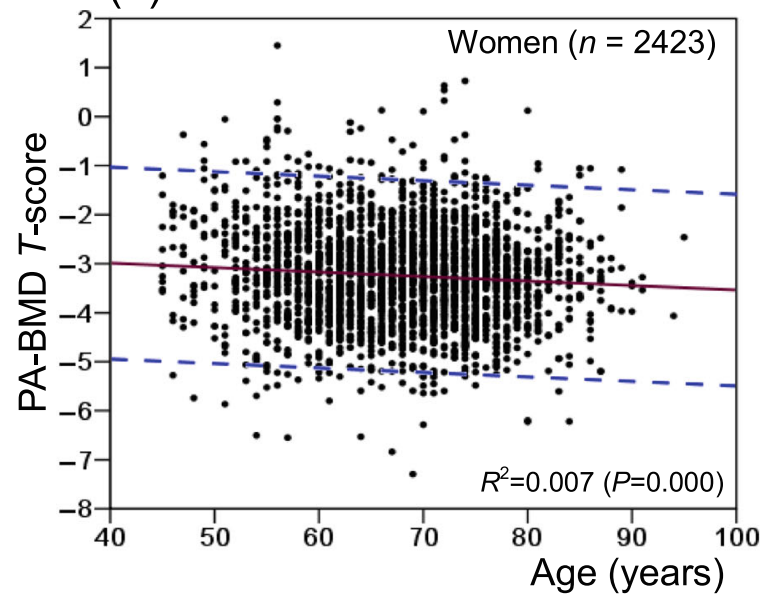

(c)

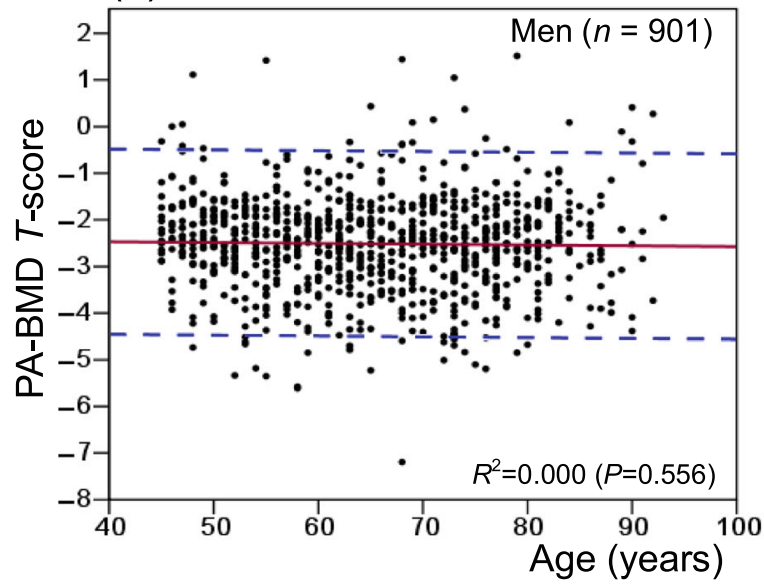

(b)

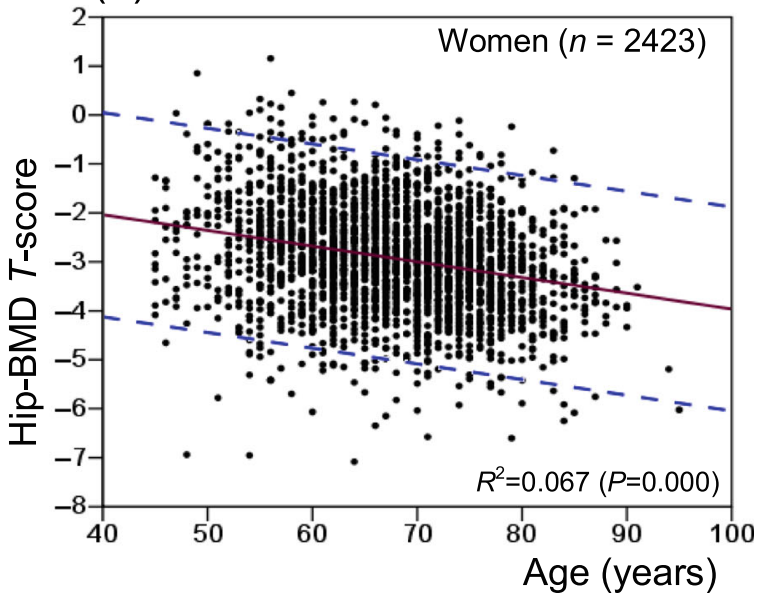

(d)

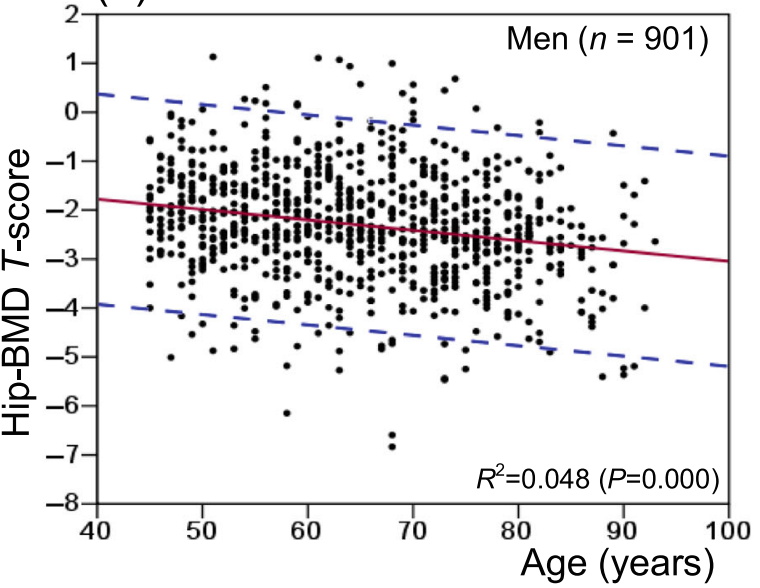

\section{$P A-B M D$ posteroanterior $(P A)$ spine bone mineral density}

Fig. 1 Distributions of T-scores and $95 \% \mathrm{Cl}$ of age-related changes in patients with osteoporotic fractures

range from -0.74 to -5.74 and -0.18 to -5.68 . In male fracture patients, lumbar spine BMD $T$-scores do not change with age, while hip BMD $T$-scores decrease with increasing age. $95 \%$ of fracture patients have lumbar spine BMD T-scores between 0.01 and - 5.04, and hip BMD $T$-scores between 0.49 and -5.11 .

\section{Rates of osteoporosis, osteopenia, and normal BMD in}

\section{fractures}

Among women with various types of fractures, the prevalence of osteoporosis in lumbar spine and hip was 78.9 and $67.2 \%$ (Fig. 2), respectively, the prevalence of osteopenia was 19.3 and $28.4 \%$ respectively and the percentage of normal BMD was 1.8 and $4.4 \%$ respectively. There are significant differences in the mean age \pm SD between osteoporosis, osteopenia, and normal BMD for both sites in women. Most female fracture patients suffer from osteoporosis and are older. Among men with various types of fractures, the prevalence of osteoporosis in lumbar spine and hip was 49.5 and $43.2 \%$ respectively, the prevalence of osteopenia was 44.8 and $45.9 \%$ respectively and the percentage of normal BMD was 5.7 and $10.9 \%$ respectively. Rates of osteoporosis, osteopenia, and normal BMD for a given skeletal site significantly differed between men and women in these fracture groups.

\section{Fracture HR}

Table 2 shows the fracture HR for female and male subjects, as determined using multivariate Cox regression analysis. BMDs and $T$-scores were stratified in descending order and analyzed. The results showed that in both male and female participants, both univariate analysis (unadjusted model) and covariance analysis (adjusted model) indicated that fracture risk ratios greatly increased with decreasing BMD and T-score. With a 


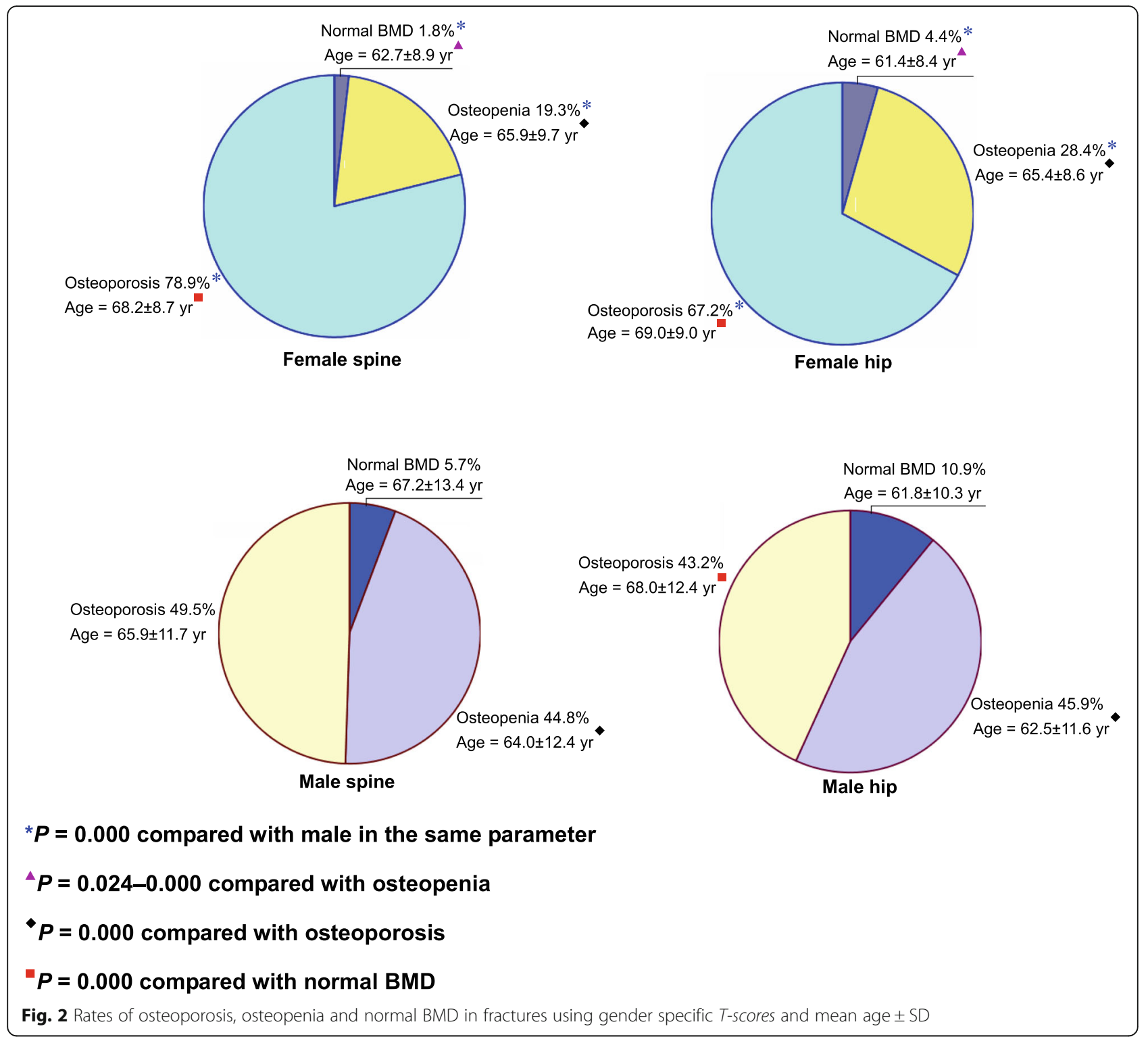

Table. 2 Multivariate Cox regression analysis of the HR for clinical patients with osteoporotic fractures

\begin{tabular}{|c|c|c|c|c|}
\hline \multirow[t]{3}{*}{ Variable } & \multicolumn{2}{|l|}{ Female (2423 pair) } & \multicolumn{2}{|l|}{ Male (901 pair) } \\
\hline & Unadjusted model $^{a}$ & Adjusted model $^{b}$ & Unadjusted model $^{a}$ & Adjusted model $^{c}$ \\
\hline & HR (95 \% Cl) & HR (95\% Cl) & HR (95\% Cl) & HR (95\% Cl) \\
\hline PA-BMD & $3.08(2.83-3.36)$ & $2.73(2.50-2.99)$ & $4.18(3.51-4.99)$ & $3.61(2.99-4.36)$ \\
\hline Hip-BMD & $3.24(2.96-3.55)$ & $2.83(2.57-3.12)$ & $4.67(3.86-5.65)$ & $4.12(3.34-5.08)$ \\
\hline PA T-score & $3.09(2.84-3.36)$ & $2.73(2.50-2.99)$ & $4.36(3.64-5.22)$ & $3.76(3.10-4.56)$ \\
\hline Per - 1 T-score & $1.73(1.67-1.80)$ & $1.72(1.65-1.78)$ & $1.76(1.68-1.85)$ & $1.68(1.59-1.78)$ \\
\hline Hip T-score & $3.24(2.96-3.55)$ & $2.83(2.57-3.12)$ & $4.62(3.83-5.59)$ & $4.06(3.29-5.00)$ \\
\hline Per - 1 T-score & $1.60(1.55-1.66)$ & $1.63(1.58-1.69)$ & $1.67(1.59-1.76)$ & $1.60(1.51-1.70)$ \\
\hline
\end{tabular}

PA-BMD posteroanterior (PA) spine bone mineral density, $95 \% \mathrm{Cl} 95 \%$ confidence interval

annivariate analysis

${ }^{\mathrm{b}}$ Adjusted for age, age at menopause, years since menopause, height, weight and body mass index

${ }^{c}$ Adjusted for age, height, weight and body mass index 
decline in PA spine BMD, HRs in adjusted model were 2.73 (95\% CI: $2.50-2.99$ ) and 3.61 (95\% CI: 2.99-4.36) for women and men, respectively. In adjusted model, 1point decrement in $T$-score at PA spine resulted in HRs of 1.72 (95\% CI: $1.65-1.78$ ) and 1.68 (95\% CI: $1.59-$ 1.78 ) for women and men, respectively.

\section{Discussion}

This case-control study involved patients with clinical fragility fracture as cases and individuals without lowimpact fractures as controls; cases and controls were fully matched for age and sex at a ratio of 1:1. Comparisons between case and control groups indicated that in both men and women, the mean BMDs and $T$-scores at different skeletal sites were significantly lower in case group than in control group. In vertebral fracture subgroup, $61 \%$ of women and $55 \%$ of men had multiple vertebral fractures, and average lumbar BMDs in both men and women were significantly lower than those in hip and other fracture subgroups. In other fracture subgroup, $85 \%$ of women and $80 \%$ of men had distal forearm and wrist fractures, and average age was the lowest in this subgroup. However, mean BMDs and T-scores at each skeletal site were highest in other fracture subgroup, and significantly differed from those in vertebral and hip fracture subgroups. The younger age and relatively greater mean BMDs and $T$-scores among patients with distal forearm fractures may be attributable to the fact that during falls, younger patients were able to extend their arms faster in order to protect other parts of the body. However, with increasing age, the speed at which arms are extended during falls decreases [31], and therefore, the incidence of distal forearm fractures may decrease, while the probability of hip fracture may increase, after age of 65 years, especially in women. Thus, fragility fractures of distal forearm are common among older people with relatively young age and a relatively healthy body [32].

In this study, we used a proprietary sex-specific BMD reference database $[27,28]$, with representative $T$-scores, that we had established previously by ourselves. Thus, diagnoses of osteoporosis, osteopenia, and normal BMD in our present study were accurate and reliable. We hope that through our articles not only exhibit the relationship between BMD and fragility fracture risk in native Chinese, but also show more representative research results to colleagues, which can be meaningful contribution to construct Chinese data. Our results showed that among women with clinical fragility fractures in Changsha, China, the prevalence of osteoporosis of lumbar spine and hip was 78.9 and $67.2 \%$ respectively. However, among men with clinical fragility fractures, the prevalence of osteoporosis of lumbar spine and hip was 49.5 and $43.2 \%$ respectively. This suggested that osteoporosis is more common in women with fragility fractures than in men. However, the prevalence of fragility fracture was higher in men with osteopenia than in women, and the distribution of BMD $T$-scores among patients with clinical fragility fractures exhibited obvious sex-based differences. A follow-up population-based study showed that osteoporosis was present in $44 \%$ of women with nonvertebral fractures and $64 \%$ of women with hip fractures, but in only $21 \%$ of men with non-vertebral fractures and $39 \%$ of men with hip fractures [33]. Our results confirmed that clinical fragility fractures were more common among patients (both women and men) with osteoporosis, but the difference in both sexes seemed to be similar. Despite an increase in the incidence of fractures in postmenopausal women with osteoporosis, most fragility fractures (60-68\%) occur in non-osteoporotic women [34], and this ratio was even higher in a study that used peripheral bone BMD $T$ scores analysis [33]. Higher incidence of fragility fractures among osteopenic individuals may be attributable to the fact that osteopenia is much more prevalent than osteoporosis [34-36]. BMD is the main important determinant of osteoporotic fractures; other factors include aging, low BMI, history of falls, previous fracture, smoking, excessive alcohol consumption, long-term glucocorticoid use, long-acting benzodiazepine or anticonvulsant therapy, hypogonadism, long-term caffeine consumption, stroke, diabetes, non-alcoholic fatty liver, low grip strength, high-fat diet, complications, and comorbidity [7, 22, 37-41]. Increased body weight, walking, physical activity, increased muscle strength, and greater intake of fruits and vegetables may reduce the risk of fracture [22, 40, 42].

As previously stated, BMD is the main important determinant of osteoporotic fractures. In general, HRs were smaller after model adjustment, indicating that the effects of BMD and $T$-scores on fracture risk decline after elimination of the effects of covariates such as age, age at menopause, years since menopause, height, weight, and body mass index. We stratified $T$-scores using 1-point decrements, and obtained HRs of 1.631.72 among women; this indicates that fracture risk in women increased by 1.6-1.7 times for every 1-point decrease in $T$-score. However, in men, this risk increased by $1.6-2.0$ times. Our results are similar to the results of many epidemiological follow-up studies [23-26, 33].

Since this study was not a follow-up investigation, its primary limitation is that the results obtained may not necessarily represent a causal relationship. Another limitation of this study is that histories of other related diseases and drug use, family history of fracture, and bone turnover markers related to bone metabolism were not assessed. All these factors are also associated with fragility fracture risk [22, 38, 43]. 


\section{Conclusions}

Based on the relationship investigation between BMD measurement parameters and risk of fragility fractures in mainland China, our findings state that risk of clinical osteoporotic fracture increases with decreasing BMD measurement parameters and anthropometric indicators, and fracture HR exhibits obvious sex- and site-based differences. These could provide helpful guidance for clinicians to prevent fragility fractures.

\section{Abbreviations}

BMD: Bone mineral density; DXA: Dual-energy X-ray absorptiometry; HR: Hazard ratio; PA: Posteroanterior; RMSCV: Root-mean-square coefficient of variation; WHO: World Health Organization; Cl: Confidence interval; PABMD: Posteroanterior (PA) spine bone mineral density.

\section{Acknowledgements}

The author would like to thank the patients and their family members for their help and informed consent.

\section{Authors' contributions}

HLL was the main writer of the paper, HLL and XYW conceived the study idea and design, conducted part of the analysis and interpretation of the data. YS, LHT, and RCD participated in the experiment and data collection of the study. LQY and RCD conducted patient monitoring. SBF, ZFS, and ZJX contributed to the analysis and interpretation of the study. XPW, EYL, and $\mathrm{XLT}$ contributed to proofreading and revision of the manuscript. All authors have read and approved the manuscript.

\section{Funding}

This work was supported in part by grants from the National Natural Science Foundation of China (Grant No. 81500685) and the Ministry of Health of the People's Republic of China (No. 200446850).

\section{Availability of data and materials}

All data analyzed during this study are included in this published article.

\section{Declarations}

\section{Ethics declarations}

This study was approved by the Ethics Committee of Second Xiangya Hospital affiliated to Central South University in China. All subjects provided informed consent to take part in the study. All procedures were conducted according to the 1964 Declaration of Helsinki and its amendments.

\section{Consent for publication}

Not applicable.

\section{Competing interests}

The authors declare that they have no competing interests.

\section{Author details}

'National Clinical Research Center for Metabolic Diseases, Department of Metabolism and Endocrinology, Hunan Provincial Key Laboratory for Metabolic Bone Diseases, The Second Xiangya Hospital, Central South University, No.139 Middle Renmin Road, 410011 Changsha, Hunan, PR China. ${ }^{2}$ Department of Endocrinology, The First Hospital of Lanzhou University, No.1 DongGang West Road, 730000 Lanzhou, Gansu Province, PR China. ${ }^{3}$ Department of Orthopaedics, The Second Xiangya Hospital, Central South University, No.139 Middle Renmin Road, 410011 Changsha, Hunan, PR China. ${ }^{4}$ Department of Radiology, The Second Xiangya Hospital, Central South University, No.139 Middle Renmin Road, 410011 Changsha, Hunan, PR China.

Received: 19 January 2021 Accepted: 13 August 2021

Published online: 24 August 2021

\section{References}

1. Leslie WD. Clinical review: Ethnic differences in bone mass-clinical implications. J Clin Endocrinol Metab 2012; 97:4329-40.
2. Bliuc D, Nguyen TV, Eisman JA, Center JR. The impact of non-hip nonvertebral fractures in elderly women and men. J Clin Endocrinol Metab 2014; 99:415-23.

3. Brauer CA, Coca-Perraillon M, Cutler DM, Rosen AB. Incidence and mortality of hip fractures in the United States. JAMA 2009; 302:1573-9.

4. Leslie WD, Brennan SL, Prior HJ, Lix LM, Metge C, Elias B. The contributions of First Nations ethnicity, income, and delays in surgery on mortality postfracture: a population-based analysis. Osteoporos Int 2013; 24:1247-56.

5. Tran T, Bliuc D, Hansen L, Abrahamsen B, van den Bergh J, Eisman JA, et al. Persistence of Excess Mortality Following Individual Nonhip Fractures: A Relative Survival Analysis. J Clin Endocrinol Metab 2018; 103(9):3205-14.

6. Burge R, Dawson-Hughes B, Solomon DH, Wong JB, King A, Tosteson A. Incidence and economic burden of osteoporosis-related fractures in the United States, 2005-2025. J Bone Miner Res 2007; 22:465-75.

7. Weaver J, Sajjan S, Lewiecki EM, Harris ST, Marvos P. Prevalence and Cost of Subsequent Fractures Among U.S. Patients with an Incident Fracture. J Manag Care Spec Pharm 2017; 23(4):461-71.

8. Singer A, Exuzides A, Spangler L, O'Malley C, Colby C, Johnston K, et al. Burden of illness for osteoporotic fractures compared with other serious diseases among postmenopausal women in the United States. Mayo Clin Proc 2015; 90(1):53-62

9. Pike C, Birnbaum HG, Schiller M, Swallow E, Burge RT, Edgell ET. Economic burden of privately insured non-vertebral fracture patients with osteoporosis over a 2-year period in the US. Osteoporos Int 2011; 22:47-56.

10. Barrett-Connor E, Siris ES, Wehren LE, Miller PD, Abbott TA, Berger ML, et al. Osteoporosis and fracture risk in women of different ethnic groups. J Bone Miner Res 2005; 20:185-94.

11. Cauley JA, Lui LY, Ensrud KE, Zmuda JM, Stone KL, Hochberg MC, et al. Bone mineral density and the risk of incident nonspinal fractures in black and white women. JAMA 2005; 293:2102-8.

12. Bow $\mathrm{CH}$, Cheung E, Cheung $\mathrm{CL}$, Xiao SM, Loong C, Soong C, et al. Ethnic difference of clinical vertebral fracture risk. Osteoporos Int 2012; 23:879-85.

13. Leslie WD, O'Donnell S, Lagacé C, Walsh P, Bancej C, Jean S, et al. Population-based Canadian hip fracture rates with international comparisons. Osteoporos Int 2010; 21:1317-22.

14. Chie WC, Yang RS, Liu JP, Tsai KS. High incidence rate of hip fracture in Taiwan: estimated from a nationwide health insurance database. Osteoporos Int 2004; 15:998-1002.

15. Xia WB, He SL, Xu L, Liu AM, Jiang Y, Li M, et al. Rapidly increasing rates of hip fracture in Beijing, China. J Bone Miner Res 2012; 27:125-9.

16. Wright NC, Saag KG, Curtis JR, Smith WK, Kilgore ML, Morrisey MA, et al. Recent trends in hip fracture rates by race/ethnicity among older US adults. J Bone Miner Res 2012; 27:2325-32.

17. Hopkins RB, Pullenayegum E, Goeree R, Adachi JD, Papaioannou A, Leslie WD, et al. Estimation of the lifetime risk of hip fracture for women and men in Canada. Osteoporos Int 2012; 23:921-7.

18. Xu L, Lu A, Zhao X, Chen X, Cummings SR. Very low rates of hip fracture in Beijing, People's Republic of China the Beijing Osteoporosis Project. Am J Epidemiol 1996; 144:901-7.

19. Cooper C, Campion G, Melton $\amalg$ 3rd. Hip fractures in the elderly: a worldwide projection. Osteoporos Int 1992; 2:285-9.

20. Cummings SR, Black DM, Nevitt MC, Browner W, Cauley J, Ensrud K, et al. Bone density at various sites for prediction of hip fractures. The Study of Osteoporotic Fractures Research Group. Lancet 1993; 341:72-5.

21. Leslie WD, Metge C, Ward L. Contribution of clinical risk factors to bone density-based absolute fracture risk assessment in postmenopausal women. Osteoporos Int 2003; 14:334-8.

22. Cummings SR, Nevitt MC, Browner WS, Stone K, Fox KM, Ensrud KE, et al. Risk factors for hip fracture in white women. Study of Osteoporotic Fractures Research Group. N Engl J Med 1995; 332:767-73.

23. Hillier TA, Stone KL, Bauer DC, Rizzo JH, Pedula KL, Cauley JA, et al. Evaluating the value of repeat bone mineral density measurement and prediction of fractures in older women: the study of osteoporotic fractures. Arch Intern Med 2007; 167:155-60.

24. Marshall $\mathrm{D}$, Johnell $\mathrm{O}$, Wedel $\mathrm{H}$. Meta-analysis of how well measures of bone mineral density predict occurrence of osteoporotic fractures. BMJ 1996: 312:1254-9.

25. Johnell O, Kanis JA, Oden A, Johansson H, De Laet C, Delmas P, et al. Predictive value of BMD for hip and other fractures. J Bone Miner Res 2005; 20:1185-94. 
26. Cauley JA, Hochberg MC, Lui LY, Palermo L, Ensrud KE, Hillier TA, et al. Long-term risk of incident vertebral fractures. JAMA 2007; 298:2761-7.

27. Wu XP, Liao EY, Zhang H, Shan PF, Cao XZ, Liu SP. Establishment of BMD reference plots and determination of peak BMD at multiple skeletal regions in mainland Chinese women and the diagnosis of osteoporosis. Osteoporos Int 2004; 15:71-9.

28. Wu XP, Hou YL, Zhang H, Shan PF, Zhao Q, Cao XZ, et al. Establishment of $\mathrm{BMD}$ reference databases for the diagnosis and evaluation of osteoporosis in central southern Chinese men. J Bone Miner Metab 2008; 26:586-94.

29. Genant HK, Wu CY, van Kuijk C, Nevitt MC. Vertebral fracture assessment using a semiquantitative technique. J Bone Miner Res 1993; 8:1137-48

30. Kanis JA, McCloskey EV, Johansson H, Oden A, Melton $\sqcup$ 3rd, Khaltaev N. A reference standard for the description of osteoporosis. Bone 2008; 42:46775.

31. Cummings SR. Prevention of hip fractures in older women: a populationbased perspective. Osteoporos Int 1998; 8(Suppl 1):S8-12.

32. Graafmans WC, Ooms ME, Bezemer PD, Bouter LM, Lips P. Different risk profiles for hip fractures and distal forearm fractures: a prospective study. Osteoporos Int 1996; 6:427-31.

33. Schuit SC, van der Klift M, Weel AE, de Laet CE, Burger H, Seeman E, et al. Fracture incidence and association with bone mineral density in elderly men and women: the Rotterdam Study. Bone 2004; 34:195-202.

34. Cranney A, Jamal SA, Tsang JF, Josse RG, Leslie WD. Low bone mineral density and fracture burden in postmenopausal women. CMAJ 2007; 177: 575-80.

35. Siris ES, Chen YT, Abbott TA, Barrett-Connor E, Miller PD, Wehren LE, et al. Bone mineral density thresholds for pharmacological intervention to prevent fractures. Arch Intern Med 2004; 164:1108-12.

36. Pasco JA, Seeman E, Henry MJ, Merriman EN, Nicholson GC, Kotowicz MA. The population burden of fractures originates in women with osteopenia, not osteoporosis. Osteoporos Int 2006; 17:1404-9.

37. Kung AW, Lee KK, Ho AY, Tang G, Luk KD. Ten-year risk of osteoporotic fractures in postmenopausal Chinese women according to clinical risk factors and BMD T-scores: a prospective study. J Bone Miner Res 2007; 22: 1080-7.

38. Drake MT, Murad MH, Mauck KF, Lane MA, Undavalli C, Elraiyah T, et al. Clinical review. Risk factors for low bone mass-related fractures in men: a systematic review and meta-analysis. J Clin Endocrinol Metab 2012; 97: 1861-70.

39. Zeng FF, Wu BH, Fan F, Xie HL, Xue WQ, Zhu HL, et al. Dietary patterns and the risk of hip fractures in elderly Chinese: a matched case-control study. J Clin Endocrinol Metab 2013; 98:2347-55.

40. Määttä M, Terho E, Jokinen H, Pulkkinen P, Korpelainen J, Heikkinen J, et al. Lifestyle factors and site-specific risk of hip fracture in community dwelling older women-a 13-year prospective population-based cohort study. BMC Musculoskelet Disord 2012; 13:173.

41. Sheehan KJ, Sobolev B, Chudyk A, Stephens T, Guy P. Patient and system factors of mortality after hip fracture: a scoping review. BMC Musculoskelet Disord 2016; 17(1):166.

42. Zeng FF, Fan F, Xue WQ, Xie HL, Wu BH, Tu SL, et al. The association of red meat, poultry, and egg consumption with risk of hip fractures in elderly Chinese: a case-control study. Bone 2013; 56:242-8.

43. Ivaska KK, Gerdhem P, Väänänen HK, Akesson K, Obrant KJ. Bone turnover markers and prediction of fracture: a prospective follow-up study of 1040 elderly women for a mean of 9 years. J Bone Miner Res 2010; 25:393-403.

\section{Publisher's Note}

Springer Nature remains neutral with regard to jurisdictional claims in published maps and institutional affiliations.

Ready to submit your research? Choose BMC and benefit from:

- fast, convenient online submission

- thorough peer review by experienced researchers in your field

- rapid publication on acceptance

- support for research data, including large and complex data types

- gold Open Access which fosters wider collaboration and increased citations

- maximum visibility for your research: over $100 \mathrm{M}$ website views per year

At $\mathrm{BMC}$, research is always in progress.

Learn more biomedcentral.com/submissions 